\title{
A Case Report on Left Sided Primary Petit’s Triangle Hernia
}

\author{
Ramesh Mahadev Tambat ${ }^{1}$, Nitin Kumar K ${ }^{1}$, P Rajshekhar Rao ${ }^{1}$, Sadiq Nawaz F $^{1}$, Arshiya Sultana \\ Khanum $^{1}$, Himaja Samanthapudi ${ }^{1}$, Yogendra Shrestha ${ }^{2 *}$ and Jeet Bahadur Moktan ${ }^{2}$
}

${ }^{1}$ Department of General Surgery, Sapthagiri Institute of Medical Sciences and Research Institute, India

${ }^{2}$ Department of Pharmacy Practice, Sri Adichunchanagiri College of Pharmacy, Adichunchanagiri University, India

*Corresponding author: Shrestha Y, Research Scholar, Department of Pharmacy Practice, Sri Adichunchanagiri College of Pharmacy, Adichunchanagiri University, BG Nagara-571448, Karnataka, India, Tel: +917348944358; E-mail: dryogendrastha@gmail.com

Received: September 01, 2021; Accepted: September 14, 2021; Published: September 21, 2021

\begin{abstract}
Lumbar hernias, on the other hand, are uncommon and rarely reported. Trauma, surgery, and infection are all common causes. They're becoming more common as a result of injuries sustained in motor vehicle collisions. Different surgical approaches and methods are used to treat it, and mesh placement is required for better results. It had created increased diagnostic and therapeutic problems to surgeons because of its rarity. CT scan remain best option for the confirming diagnosis. Here we are presenting a case report on left primary petit's triangle hernia repaired with meshplasty.
\end{abstract}

Keywords: Petit's triangle hernia; Primary lumbar hernia; Mesh repair

\section{Introduction}

Lumbar hernias account for fewer than $15 \%$ of all abdominal hernias when compared to all other ventral abdominal wall hernias. A congenital or acquired deficiency in the posterolateral abdominal wall causes the protrusion of an organ (intraperitoneal or extraperitoneal) or extraperitoneal tissue. Age, obesity, extreme thinness, chronic debilitating disease, muscular atrophy, excessive slimming, chronic bronchitis, wound infection, and surgical sepsis are all predisposing factors in spontaneous developed lumbar hernia. They're also frequently linked to high-intensity exercise. The loss of fatty tissue appears to accelerate the rupture of the neurovascular orifices that penetrate the lumbodorsal fascia, and conditions involving increased intra-abdominal pressure appear to be triggers for the formation of these hernias. In our example, this morbidly obese individual has been carrying enormous weights by hand. Lumbar hernia is a rather uncommon occurrence [1]. The external oblique muscle runs laterally, the iliac crest runs superiorly, the erector spinae muscles run medially, and the $12^{\text {th }}$ rib runs superiorly. Lumbar

Citation: Tambat RM, Nitin KK, Rao PR, et al. A Case Report on Left Sided Primary Petit's Triangle Hernia. Clin Case Rep Open Access. 2021;4(3):193. 
www.yumedtext.com | September-2021 | ISSN: 2582-5038 | https://dx.doi.org/10.46527/2582-5038.193

hernias can develop in either the superior or inferior lumbar regions, both of which are vulnerable areas. The iliac crest inferiorly, external oblique muscle laterally, and latissimus dorsi muscle medially define the inferior lumbar gap. The superior lumbar space, which is the largest of the two, has been discovered. It is an inverted triangle with the $12^{\text {th }}$ rib and the lower edge of the serratus posterior inferior muscle forming the base, the internal oblique muscle forming the anterior boundary, and the external oblique and latissimus dorsi forming the roof. It was once thought that inferior lumbar hernias were more prevalent, however subsequent research has revealed that superior triangular hernias are far more common [2]. P. Barbette was the one who first mentioned lumbar hernia. Barbette published the first case in 1672, and R.J.C. Garangeot published the first case in 1731. Only roughly 300 cases have been recorded in the literature since then [3]. A general surgeon will only be able to treat one lumbar hernia in his lifetime, according to Hafner et al. [4]. Petit established the anatomical boundaries of the inferior lumbar triangle in 1783 [5]. The superior lumbar triangle was first described by Grynfeltt in 1866 [6]. Congenital lumbar hernias account for about $20 \%$ of all lumbar hernias [7]. Eighty percent of all lumbar hernias are acquired [8]. This article describes a case study of this uncommon variation, which was originally reported in the department of surgery at this district teaching hospital. Due to non-specific symptoms, clinical identification of this condition is difficult. Alfredo Moreno-Egea et al proposed a classification with a therapeutic aim, which identifies 4 types of hernia based on 6 criteria: size, location, contents, muscular atrophy, origin, and existence of previous recurrence (TABLE 1). The presence of 2 criteria is sufficient to define the type of hernia.,

TABLE 1. Classification of Lumbar hernias [3].

\begin{tabular}{|c|c|c|c|c|}
\hline Characteristics & Type A & Type B & Type C & Type D \\
\hline Defect Size (cm) & $<5 \mathrm{~cm}$ & 5 to $15 \mathrm{~cm}$ & $>15 \mathrm{~cm}$ & \\
\hline Location & Superior & inferior & Diffuse & \\
\hline Contents & Extra peritoneal fat & Visceral & Visceral & \\
\hline Etiology & Spontaneous & Incisional & Traumatic & \\
\hline Muscular Atrophy & No & Mild & Severe & Severe \\
\hline Recurrence & No & Yes & Yes & \\
\hline Treatment Option & $\begin{array}{c}\text { Open } \\
\text { Herniorrhaphy/Laparoscopic } \\
\text { EP/TEP }\end{array}$ & $\begin{array}{c}\text { Open/ IP } \\
\text { Laparoscopy } \\
\text { mesh repair }\end{array}$ & Open mesh repair & $\begin{array}{c}\text { Double Mesh } \\
\text { repair }\end{array}$ \\
\hline
\end{tabular}

\section{Case Report}

A 52-year-old woman reported to the surgical department at Sapthagiri Institute of Medical Science with a 10-month-old leftsided flank swelling. She gave a history of lifting heavy objects just before the development of swelling but denied a history of trauma. The swelling progressively enlarged in size and caused local discomfort like intermittent pain over the swelling (FIG. $1)$. 


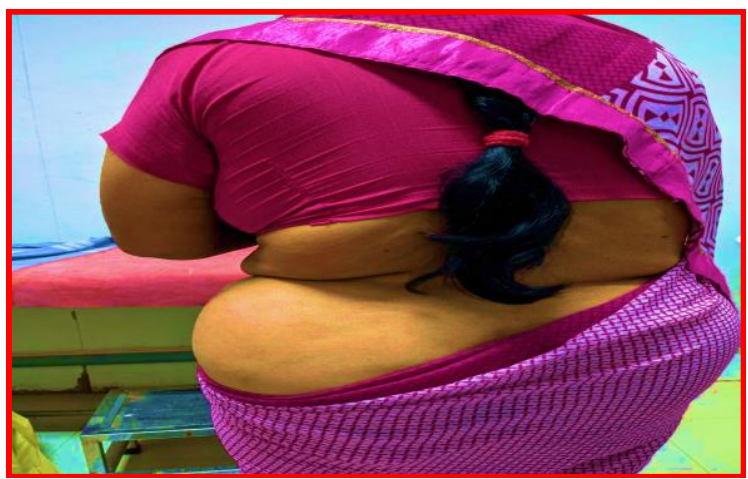

FIG. 1. External appearance of lumber hernia triangle.

On examination there was a spherical soft, non-tender swelling around $8 \mathrm{~cm}$ in diameter in the left lumbar region just above the iliac bone, with no skin changes. It was reducible with a significant visible and palpable cough impulse. CT scan of abdomen showed hernia of descending colon and its mesentery in left lower lumbar region with defect side measuring $3 \times 2.7 \mathrm{~cm}$ with no signs of obstruction (FIG. 2).

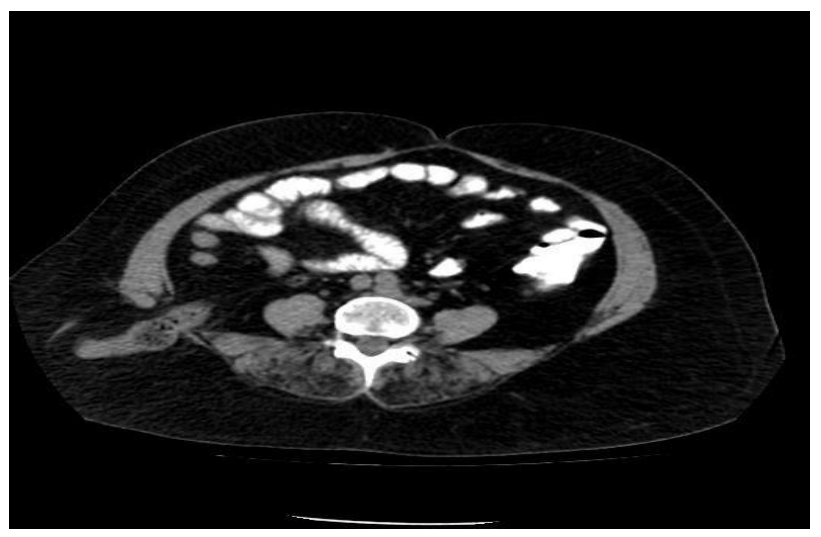

FIG. 2. CT scan shown a hernia from inferior lumbar.

A diagnosis of left lumbar hernia was made based on clinical and radiological findings. She was operated by open mesh hernioplasty. Oblique incision was made over the swelling site (FIG. 3).

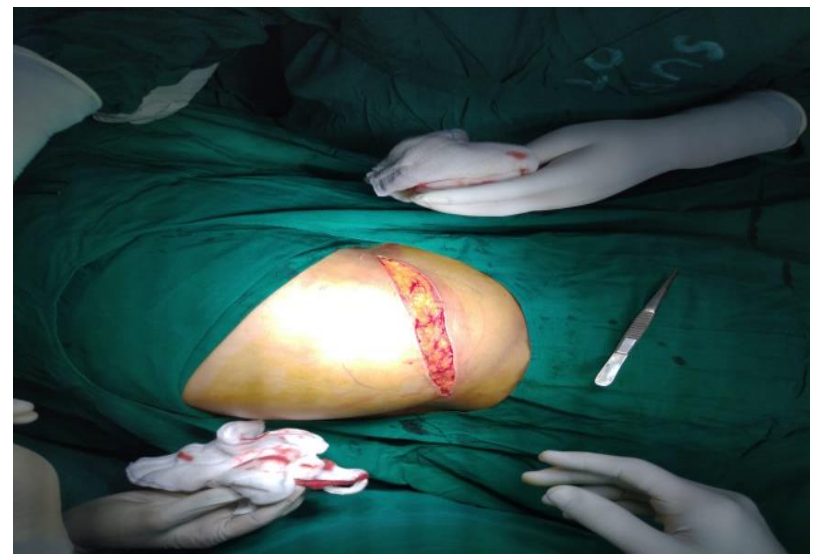

FIG. 3. Oblique incision given over the swelling triangle. 
Hernial defect was identified (FIG. 4). Contents were reduced. A patch (mesh) is placed over the defect and sutured to the external oblique and latissimus dorsi muscles, as well as to the periosteum of the iliac crest, using nonabsorbable suture (FIG. 5). The external oblique and latissimus dorsi muscles are approximated as far as possible over the patch. A second layer of mesh sutured to the muscles is used. Finally, the subcutaneous fat and skin are closed.

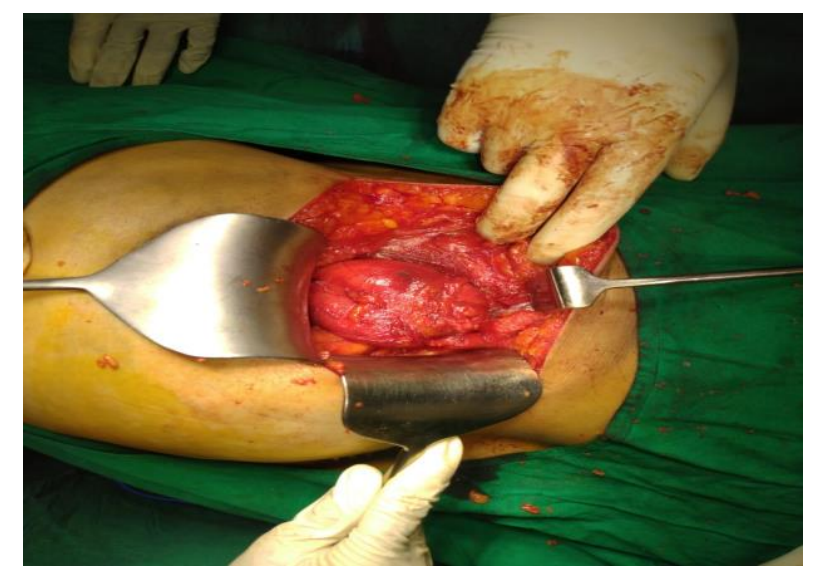

FIG. 4. Intra operative picture of hernia through inferior lumbar triangle.

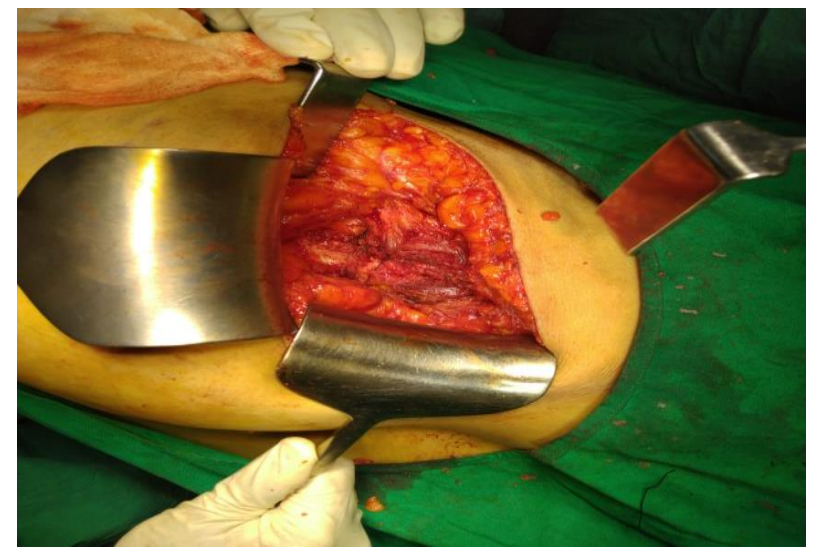

FIG. 5. Contents reduced and muscle layers approximated after placing mesh.

\section{Discussion}

The most common lumbar hernias are those of Grynfelt and Petit [9]. In 1738 petit described the anatomical borders of inferior lumbar triangle, hence the hernia through inferior lumbar triangle was named after him. The inferior lumbar triangle is an upright triangular space, bordered by the iliac crest inferiorly, the posterior border of the external abdominal oblique anteriorly, and the lateral border of the latissimus dorsi posteriorly. The roof is formed by the fascia superficialis, whereas the floor is formed by the internal oblique muscle, with contributions from the transversus abdominis muscle and the posterior lamina of the thoracolumbar fascia. Lumbar hernia can be classified into congenital and acquired [10,11]. Congenital hernias account for $20 \%$ of all lumbar hernias and appear in infancy due to a defect in the musculoskeletal system of the lumbar region [12]. They are associated with other malformations [13]. The other $80 \%$ of lumbar hernia are acquired; of which $55 \%$ are primary or spontaneous. This primary hernia is precipitated by elevated intra-abdominal pressure, such as pregnancy, obesity, ascites, or chronic bronchitis. There are also certain anatomical alterations of the posterior abdominal wall that may predispose the 
www.yumedtext.com | September-2021 | ISSN: 2582-5038 | https://dx.doi.org/10.46527/2582-5038.193

development of hernias, such as aging, muscle atrophy, debilitating disease, or extreme thinness, because loss of fatty tissue may prompt the rupture of neurovascular orifices that penetrate the thoracolumbar fascia [10]. Other $25 \%$ belongs to secondary acquired hernia [13].

Secondary lumbar hernia may be due to traumatic causes or post-surgical (flank incision, renal surgery, iliac bone harvesting). Lumbar hernia is most commonly seen in males and the vast majority is unilateral, two times more common on left side than on right [14]. Lumbar hernia usually presents as swelling at back over the posterior supra-iliac area which may be either asymptotic or associated with variable degree of pain [15]. Swelling gets reduced on lying down [10]. On performing Valsalva maneuver size of the swelling increases in size. Other symptoms may include nausea, vomiting, renal deficiency (urinary obstruction if hernia contents are renal) [16], swelling, discomfort in the lumbar region, or other clinical signs of bowel obstruction if incarcerated or strangulated [17]. If the patient has a recent trauma history the physician must look for other clinical signs, such as ecchymosis, hematomas, or the "seat belt sign"' [13].

On palpation, the weak abdominal wall area may be detected [15]. On auscultation, bowel sounds may be present over the bulge if the hernia has any bowel contents [18]. The differential diagnosis includes lipoma, soft tissue tumors, such as fibroma [19], hematoma, abscess [18], renal tumors, renal hydrocele [15], rhabdomyoma, sarcoma [20], muscle hernia, panniculitis, or pannicular lumbosacroiliac hernia [21]. CT scan is the gold standard imaging modality for diagnosing lumbar hernia, since it is able to delineate muscular and fascial layers, detect a defect in one or more of these layers, the presence of herniated contents [19], differentiate muscle atrophy from a real hernia, and serve as a useful tool in the differential diagnosis, such as tumors. Although diagnosis is mostly made on a clinical basis, given a medical history and a physical examination, CT must be used routinely in the evaluation of a patient with a lumbar hernia [18]. Surgical repair of the hernia is the only definitive treatment option. An open or laparoscopic technique may be employed. The first open repair was done in 1888 by E. Owen [17]. An oblique or vertical incision is made over the site of the hernia.

In the case of inferior triangle hernia, there was no muscular layer to cover the hernial sac. The hernial sac is freed and resected or reduced into the abdominal cavity. A patch (mesh) was placed over the defect and sutured to the external oblique and latissimus dorsi muscles, as well as to the periosteum of the iliac crest, using nonabsorbable sutures. The external oblique and latissimus dorsi muscles are approximated as far as possible over the patch, and a flap of gluteal fascia is cut. This flap of fascia is turned up to cover the remaining defect and is sutured to the approximated muscles. In the case of a large hernia ring, a second layer of mesh sutured to the muscles is used. Finally, the subcutaneous fat and skin are closed [19]. An alternative to the open approach described above is the laparoscopic approach-transabdominal or extraperitoneal of the two approaches, trans-abdominal is used more often [19,20]. It requires mobilization of the colon and kidney. The mesh is secured to the costal margin superiorly, the iliac crest periosteum inferiorly, the fascia that covers the erector spinae muscle medially, and the fascia covering the external oblique muscle laterally [22].

\section{Conclusion}

Lumber hernia is a rare disease that can make diagnosis difficult. It required careful evaluation and planning regarding operative management. CT scan remains a best option to make a diagnosis. Meshplasty is the pre- dominant method to repair, with muscle flaps used if the condition warrants it. Laparoscopic surgery also provides an alternate method of repair. 


\section{REFERENCES}

1. Stamatiou D, Skandalakis JE, Skandalakis LJ, et al. Lumbar hernia: surgical anatomy, embryology, and technique of repair. Am Surg. 2009;75(3):202-7.

2. Walgamage TB, Ramesh BS, Alsawafi Y. Case report and review of lumbar hernia. Int J Surg Case Rep. 2015;6(1):230-2.

3. Moreno-Egea A, Baena EG, Calle MC, et al. Controversies in the current management of lumbar hernias. Arch Surg. 2007;142: 82-8.

4. Hafner C, Wylie J Jr, Brush BE. Petit’s lumbar hernia: Repair with Marlex mesh. Arch Surg. 1963;86:180-6.

5. Petit JL. Traite des Maladies Chirurgicales, et des Operations qui Leur Conviennent. Paris, France. TF Didot. 1774;2:256-9.

6. Geis WP, Saletta JD. Lumbar hernia. In: Nyhus LM, Con- don RE, editors. Hernia. 3rd ed. Philadelphia: JB Lippincott, USA; 1989. 401-15 p.

7. Burt BM, Afifi HY, Wantz GE, et al. Traumatic lumbar hernia: Report of cases and comprehensive review of the literature. J Trauma. 2004;57(6):1361-70.

8. Kumar V. A Rare Case of Lumbar Hernia - A Case Report with Review of Literature. J Dent Med Sci. 2015;14(3):1013.

9. Horovitz IL, Schwarz HA, Dehan A. A lumbar hernia presenting as an obstructing lesion of the colon. Dis Colon Rectum. 1986;29(11):742-4.

10. Skandalakis JE, Colborn GL, Wiedman TA. Skandalakis' surgical anatomy: the embryologic and anatomic basis of modern surgery. Athens: Paschalidis Medical Publications, Greece; 2004. 457-60 p.

11. Standring S, Borley NR, Collins P, et al. Gray's anatomy. 40th ed. London: Churchill Livingstone, UK; 2008. 346 p.

12. Swartz WT. Lumbar hernias. J Ky Med Asssoc. 1954;52:673-8.

13. Barden BE, Maull KI. Traumatic lumbar hernia. South Med J. 2000;93:1067-9.

14. Heniford BT, Iannitti DA, Gagner M. Laparoscopic inferior and superior lumbar hernia repair. Arch Surg. 1997;132(10):1141-4.

15. Zhou X, Nve JO, Chen G. Lumbar hernia: clinical analysis of 11 cases. Hernia. 2004; 8(3):260-63.

16. Loukas M, Tubbs RS, El-Sedfy A, et al. The clinical anatomy of the triangle of Petit. Hernia. 2007;11(5):441-4.

17. Loukas M, El-Zammar D, Shoja MM, et al. The clinical anatomy of the triangle of Grynfeltt. Hernia. 2008;12(3):22731

18. Sharma P. Lumbar hernia. Med J Armed Forces India. 2009;65(2):178-9.

19. Baker ME, Weinerth JL, Andriani RT, et al. Lumbar hernia: diagnosis by CT. AJR Am J Roentgenol. 1986;148(3):565-7.

20. Owen E. Lumbar hernia: radical operation recovery. BMJ. 1888.

21. Skandalakis LJ. Modern hernia repair: the embryological and anatomical basis for surgery. Nashville: Parthenon Publishing, USA; 1996.

22. Postema RR, Bonjer HJ. Endoscopic extraperitoneal repair of a Grynfeltt hernia. Surg Endosc. 2002;16(4):716. 